\title{
DEVELOPMENT AND THEORETICAL STUDIES OF GRAIN CLEANING MACHINE FOR FRACTIONAL TECHNOLOGY OF FLATTENING FORAGE GRAIN
}

\author{
Peter Savinyh $^{1}$, Yuri Sychugov ${ }^{1}$, Vladimir Kazakov ${ }^{1}$, Semjons Ivanovs ${ }^{2}$ \\ ${ }^{1}$ North-East Agricultural Research Institute, Russia; \\ ${ }^{2}$ Latvia University of Life Sciences and Technologies, Latvia \\ semjons@apollo.lv
}

\begin{abstract}
An air screen cleaning machine has been developed for the fractional technology of forage grain flattening with a new implementation of the elements of the screen part and a pneumatic system, allowing efficient separation of the grain material coming from the field after threshing by combine harvesters into fractions of the seed and the forage grain, and their qualitative cleaning from admixtures. There is presented a design and technological scheme of this machine, as well as its pneumatic system in the form of a pneumatic circuit. Research of the pneumatic system has been carried out by mathematical simulation, which makes it possible to theoretically test its operability and conduct analysis of the dynamic processes that occur in separate elements. By using the results of these studies, a possibility appears to design and then to make a test sample of the machine with the parameters of the working tools (the pneumatic system), which ensures a qualitative cleaning process from the admixtures of the grain fractions.
\end{abstract}

Keywords: technology, fractionation, grain flattening, admixtures.

\section{Introduction}

Forage grain is valuable concentrated feed for animals, a source of carbohydrates, protein and other useful nutrients, and it is widely used in animal husbandry. To improve digestibility of its components, forage grain is subject to special processing, or grinding. One of the most economical ways of grain processing is flattening [1], which has a number of advantages in comparison with crushing [2-4], since it ensures the production of fodder best corresponding to the biochemical processes that occur in the stomach of the ruminant animal [5]. Despite the fact that grain flattening has been used for more than a hundred years, the machines for this process are constantly being improved in terms of the quality of the process performed, minimisation of the energy costs, etc.

Analysis of the scientific, technical and patent literature on the existing technologies and technical means of the post-harvest handling and processing of grain forage [6-8] shows that one of the most promising and economically profitable technologies is the fractional technology of forage grain flattening. In order to isolate the forage grain fraction (which is then subject to flattening) from the grain that is arriving after threshing by the combine harvesters on the field into the post-harvest processing centres, an air screen cleaning machine in a new design of the elements of the screen part and the pneumatic system has been developed allowing not only efficient fractionation of the not yet treated grain into the seed grain and forage, but also qualitative separation of these fractions from admixtures.

For this purpose the most perfect is the air-screen grain cleaning machine, intended for processing the grain material both in the usual mode (separation of grain from small, big and light admixtures), and in the fractionation mode (separation of the grain material into fractions with simultaneous cleaning of the grain fractions from admixtures), and a grain cleaning machine for cleaning and sizing grain $[9 ; 10]$, which performs the same functions.

Both machines reliably and qualitatively perform the technological process, but they have several disadvantages: for the first machine - the complexity of the design of the closed pneumatic system with numerous air channels, raising its price; the disadvantage of the design of the second machine the grain inlet device into the second after-screen aspiration channel runs through the first after-screen aspiration channel, which lowers the homogeneity of the airflow in the first channel and thereby degrades the quality of grain cleaning from admixtures in this channel. Consequently, there is a need to develop and optimise the parameters of a multipurpose air-screen machine, the design features of which will allow conducting the technological process of grain fractionation and cleaning from the grain fractions, including forage fraction, for more qualitative subsequent flattening. 


\section{Materials and methods}

A design and technological scheme of a multipurpose air screen machine has been developed for fractionation and cleaning the grain material from admixtures (Fig. 1) [10], which has an effective embodiment of elements of the screen part and the pneumatic system.

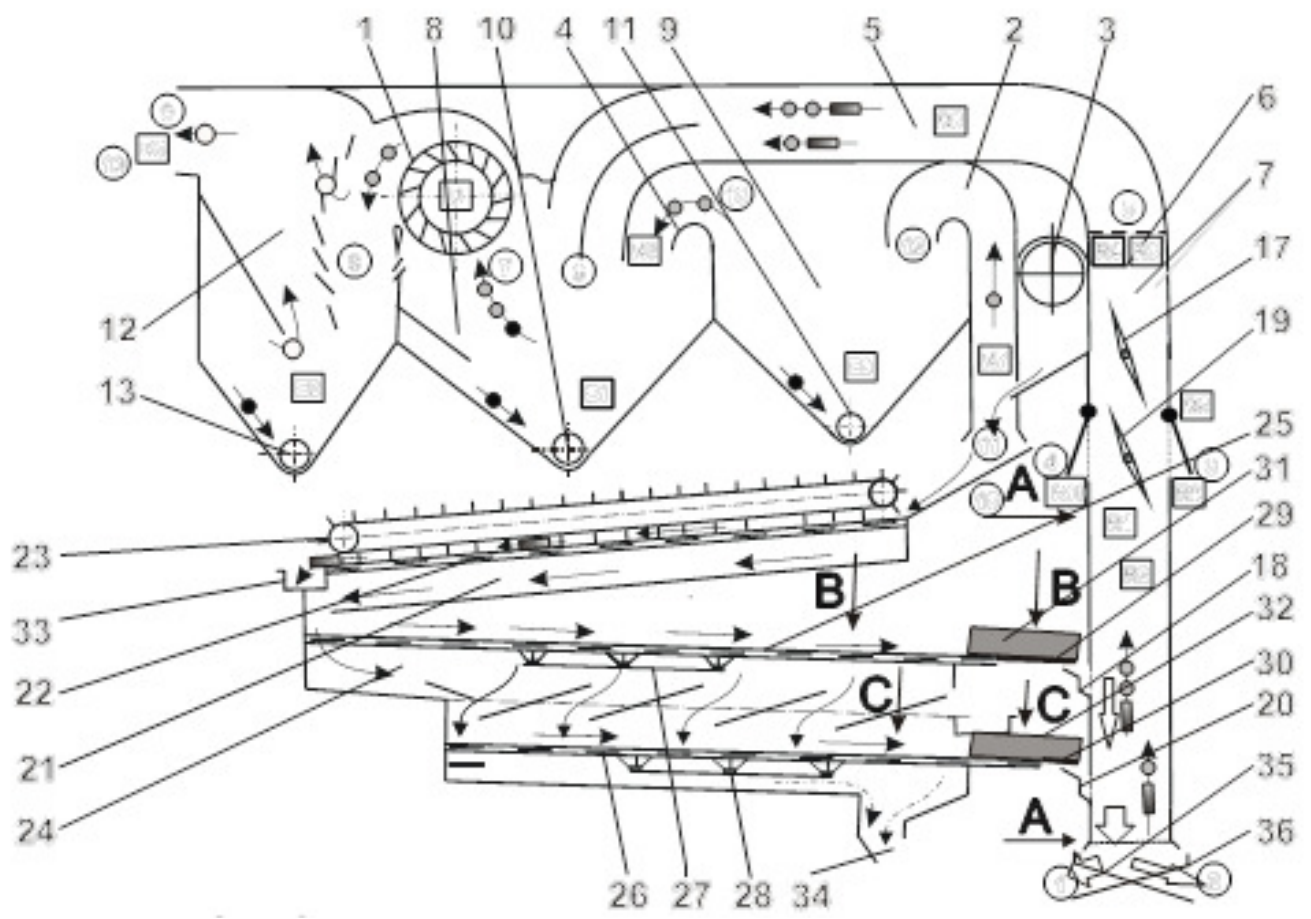

Fig. 1. Design and technological scheme of multipurpose grain cleaning machine:

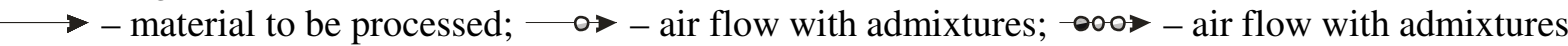
after the 2nd sedimentation chamber; $-\infty-\infty$ - air flow with admixtures after the 1 st after-screen aspiration channel; $\rightarrow 0>$ - air flow with admixtures after the 2nd after-screen aspiration channel; $\longrightarrow$ - small admixtures; $\longrightarrow-$ admixtures of the sedimentation chambers; $\longrightarrow \rightarrow$ - cleaned air; $\Rightarrow$ - cleaned grain in the second post-screen aspiration channel; $\square$ - cleaned grain in the first post-screen aspiration channel

The machine works as follows. The grain material, arriving in order to be cleaned from admixtures and fractionated by means of the feeder 3 , is fed into the pre-screen (preliminary) aspiration channel 2 (I PSC) in which, by means of the airflow generated by a transverse fan 1, the lightest admixtures are removed to the dust-settling chamber 9; they are deposited therein, and, by means of the air removal device 11, they are removed from the pneumatic system. The grain material, cleaned from the light admixtures, enters the upper layer of screens 22 of the upper screen unit 21 . From the upper layer of screens the large admixtures go downstream and, by means of the chute 33, are discharged outside, but the grain material, cleaned from large admixtures (the passage through the screens of the first layer), is delivered to the middle layer of the screens 25 of the lower screen unit 24, the screens of which are selected such that the fraction of the grain material, containing the largest grain, comes onto a chute board 29 and, by means of the plates 31, is directed to the grain inlet device 18 and, through it, into the channel 6 (II PSC), where it is cleaned from the light admixtures using an airflow, the speed of which is set by the mechanism 17; it enters the receiver 34 and, through it, is discharged from the limits of the machine. The passage through the openings of the middle layer of the screens 25 of the lower screen unit 24 extends to the lower screen layer 26 of the lower screen unit 24, through which the main part of the incoming fraction (the average-size grain) falls onto the chute board 30 and, by means of the plates 32, is directed to the grain inlet device 20 and, through it, into the channel 7 (III PSC), where it is cleaned from the light admixtures using an airflow the speed of which is set by the mechanism 19; it enters the receiver 36 and, through it, is discharged. The passage through the openings of the lower layer of the screens 26 of the lower screen unit 24 (the small organic and mineral admixtures) extends to the chute 34 and, through it, is discharged from the limits of the 
machine. Admixtures, isolated from the grain fractions in the first 6 and the second 7 post-screen aspiration channels, are carried by the airflow to the sedimentation chamber 8 , where they are deposited, and, by means of the device 10, are discharged to the outside. The used airflow, after being cleaned by the dust cleaner 12 and the transverse fan 1 , is discharged into the atmosphere.

In order to improve the efficiency of the air system of the multipurpose grain cleaning machine, research of its dynamic properties was carried out. For this purpose, the design and technological scheme of the pneumatic system of the machine (Fig. 1) from the point of view of the airflows is represented in the form of a pneumatic circuit (Fig. 2) including a series and parallel connection of several resistances, capacities and a fan that together ensure air suction from the pneumatic separating channels.

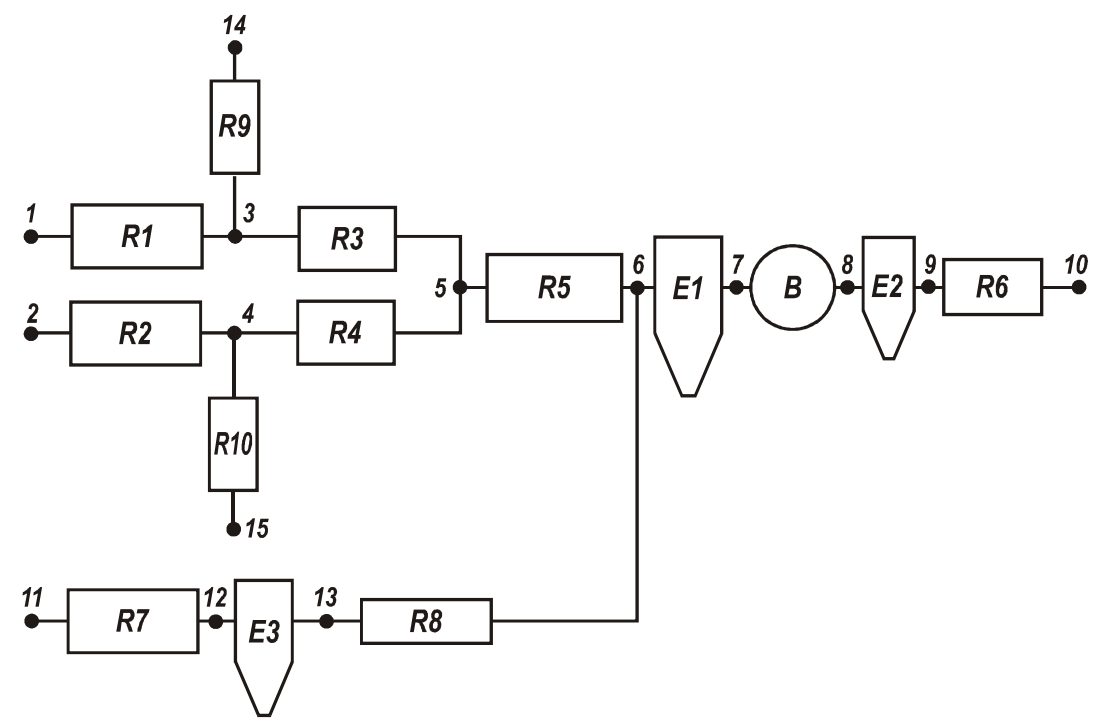

Fig. 2. Scheme of pneumatic circuit of air system of multipurpose grain cleaning machine:

$R 1$ - resistance of the first pneumatic separating channel; $R 2$ - resistance of the second pneumatic separating channel; $R 7$ - resistance of the pre-screen aspiration channel $R 3 \ldots R 6 ; R 8 \ldots R 10$ - network resistance constants; $E 1 ; E 2 ; E 3$ - capacities of the sedimentation chambers; $B$ - the fan;

$$
1 \text {... } 15 \text { - nodal points }
$$

Selecting several elements of the circuit, different by their structure, it is possible to create idealised models for each of them. The airflow in the elements is described by the methods of hydraulics, but their connection and joint operation - by the methods of pneumatic circuits. In this circuit (Fig. 2) 1, 2, .. 15 are the nodal points. The transmitted parameters are the airflow velocities $v_{i}$ and static pressures $P_{i}(i=1, \ldots, 15) ; R_{1}, \ldots, R_{10}$ - hydraulic resistances including the resistances of the pipelines, local resistances, and internal resistances of neighbouring devices. Values $R_{1}, R_{2}, R_{7}$ are variable since the pulsations of the material supply create resistance fluctuations in the pneumatic separating channels. Fan B and capacities $E_{1}, E_{2}, E_{3}$ are network elements connected by resistances $R_{i}$.

In idealisation, only one determining effect is selected and taken into account for each element (for example, the inertia of the flow or its compressibility, etc.), but all the other properties are ascribed to the neighbouring elements. So, the resistance of the sedimentation chambers, for instance, $E_{1}$, is considered as part of the previous resistances $R_{5}$ and $R_{8}$, and in element $E_{1}$ itself we describe only the pressure changes due to the difference of flows at the inlet and the outlet [11]:

$$
\frac{V_{C}}{a^{2}} \cdot \frac{d P_{7}}{d t}=Q_{6}-Q_{7}
$$

where $V_{C}$ - volume of the sedimentation chamber, $\mathrm{m}^{3}$;

$a^{2}$ - square of the sound velocity in the air, $\mathrm{m} \cdot \mathrm{s}^{-1}$;

$P_{7}$ - pressure in the tank, $\mathrm{Pa}$ (with $P_{7}=P_{6}$ );

$t$ - time, $\mathrm{s}$;

$Q_{6}=v_{6} \cdot F_{6}$ - air flow rate at the inlet to the container, $\mathrm{m}^{3} \cdot \mathrm{s}^{-1}$;

$Q_{7}=v_{7} \cdot F_{7}-$ air flow rate at the outlet from the container, $\mathrm{m}^{3} \cdot \mathrm{s}^{-1}$; 
$v_{i}$ - average velocities at the corresponding nodal points, $\mathrm{m} \cdot \mathrm{s}^{-1}$;

$F_{i}$ - cross-sectional areas of the channels at the nodal points, $\mathrm{m}^{2}$.

In the containers of the sedimentation chambers $E_{2}, E_{3}$ similar dependences can be presented to describe the process of the pressure change. As a number of experiments showed, at the investigation stage of the dynamics of the branched pneumatic system with several parallel connections, it is purposeful to exclude containers, when considering the equation of the form (1) in order to increase the stability of the process of the numerical solution of a system of differential equations. The properties of the sedimentary chambers as containers must be investigated separately, separating them from the pneumatic circuit, after that only the hydraulic resistance in the sedimentary chambers was taken into consideration.

When considering the fan $B$ as an element of the pneumatic circuit, we take into account only the relationship between the flow rate $Q_{8}=v_{8} \cdot F_{8}$ and the difference of pressures at the inlet $P_{7}$ and the outlet $P_{8}$ from the device in accordance with its characteristic.

In the experiment (calculation of dependencies), barley (the "Hlynovsky" variety) was used.

\section{Results and discussion}

If we approximate the dependence of the static pressure upon the velocity at the outlet from the pneumatic system by some function $f(v)$, then the mathematical model of the fan can be represented by an algebraic equation [12]:

$$
P_{7}-P_{8}=f\left(v_{8}\right)
$$

When describing the characteristics of the pneumatic system with a parabola, we have:

$$
P_{7}-P_{8}=P_{O B}-k_{B} v_{8}^{2}
$$

where $P_{O B}, k_{B}$-constants determined as a result of approximation of the fan characteristics.

We will build a differential equation describing the movement of the airflow in the PSC $\left(R_{1}, R_{2}\right.$, $R_{7}$ ), based on the Bernoulli equation:

$$
\begin{gathered}
R_{1}: \rho \cdot L_{1} \cdot \frac{d v_{1}}{d t}=\left(P_{1}-P_{3}\right)-\rho \cdot \lambda_{1} \cdot \frac{v_{1}^{2}}{2}-\rho \cdot\left(A_{1} \cos \omega_{1} \cdot t\right) \cdot \frac{v_{1}^{2}}{2}+\frac{\rho}{2} \cdot\left(v_{1}^{2}-v_{3}^{2}\right), ; \\
R_{2}: \rho \cdot L_{2} \cdot \frac{d v_{2}}{d t}=\left(P_{2}-P_{4}\right)-\rho \cdot \lambda_{2} \cdot \frac{v_{2}^{2}}{2}-\rho \cdot\left(A_{2} \cos \omega_{2} \cdot t\right) \cdot \frac{v_{2}^{2}}{2}+\frac{\rho}{2} \cdot\left(v_{2}^{2}-v_{4}^{2}\right), ; \\
R_{7}: \rho \cdot L_{7} \cdot \frac{d v_{7}}{d t}=\left(P_{11}-P_{12}\right)-\rho \cdot \lambda_{7} \cdot \frac{v_{7}^{2}}{2}-\rho \cdot\left(A_{7} \cos \omega_{7} \cdot t\right) \cdot \frac{v_{7}^{2}}{2}+\frac{\rho}{2} \cdot\left(v_{11}^{2}-v_{12}^{2}\right), ;
\end{gathered}
$$

where $\lambda_{1}, \lambda_{2}, . \lambda_{7}$ - resistance coefficients, determined in an experimental way, for the third, second and first pneumatic separating channels (PSC) at various airflow rates, including the average resistance value of the grain layer on the site, as well as local resistances at the inlet and outlet of the channel;

$A_{1,2,7}$ - amplitude value of the resistance of the grain layer, $\mathrm{Pa}$ (which varies with frequency $\omega_{1,2,7}$;

$L_{1,2,7}$ - length of the first section of the pneumatic circuit, m;

$\rho$ - density of the air-product flow, $\mathrm{kg} \cdot \mathrm{m}^{-3}$.

The remaining resistances $R_{3}, R_{4}, R_{5}, R_{6}, R_{7}, R_{8}, R_{9}, R_{10}$ are described by similar differential equations, only without a periodic summand, since, after the passing the air-separating channel, the resistance of dispersed particles in the airflow stabilises.

After adding to equations (3) ... (6) the relations of the form:

$$
\begin{aligned}
& Q_{3}=Q_{1}+Q_{14} ; \\
& Q_{4}=Q_{2}+Q_{15} ;
\end{aligned}
$$




$$
\begin{gathered}
Q_{5}=Q_{3}+Q_{4} ; \\
Q_{6}=Q_{5}+Q_{13} ; \\
Q_{13}=Q_{12}=Q_{11} ; \\
Q_{10}=Q_{9}=Q_{9}=Q_{7}=Q_{6} .
\end{gathered}
$$

In addition

$$
\begin{gathered}
P_{1}=P_{2}=P_{11}=P_{10}=P_{a} ; \\
P_{6}=P_{7} ; \\
P_{12}=P_{13} ; \\
P_{8}=P_{9} ; \\
P_{3}=P_{3}^{c p} ; \\
P_{4}=P_{4}^{c p} ; \\
P_{5}=P_{5}^{c p} ; \\
P_{6}=P_{6}{ }^{c p} .
\end{gathered}
$$

where $Q_{1} \ldots-Q_{13}-$ airflow rate at the nodal points, $\mathrm{m}^{3} \mathrm{~s}$;

$P_{a}-$ atmospheric pressure, $\mathrm{Pa}$;

$P_{1, \ldots} P_{13}$ - air pressure at the nodal points, $\mathrm{Pa}$;

$P_{i}^{c p}-$ average air pressure at the $i$-th nodal point, $\mathrm{Pa}$.

As a result, we obtain a closed system of equations for 15 unknown velocities $v_{i}$ and pressures $P_{i}$ at the nodal points.

The solution of this system of equations is carried out by the Runge-Kutta method for various values of the frequency of the input action $\omega$ and by varying the parameters of the pneumatic circuit, using a package of computer programmes.

Application of these approaches makes it possible to assess the stability of the performance of the air system, for example, the dynamic characteristics of airflows in the pneumatic channels at different modes of operation of the fan; and there is also a possibility of graphical displaying changes in the airflow velocity $v$ in the PSC in time (Fig.3), when the resistance of the grain layer in pneumatic separating channels changes, and at various input frequencies of the input impact $\omega$. Fig. 3, a shows a change in the airflow velocity in the pneumatic separating channels (PSC) in time, when the resistance of the grain layer changes in the first air-separating channel (I PSC) with a frequency of the input impact $\omega_{1}=10 \mathrm{rad} \cdot \mathrm{s}^{-1}$ at $\omega_{2}=\omega_{7}=0 \mathrm{rad} \cdot \mathrm{s}^{-1}$. When the resistance of the grain layer changes with the frequency of the input impact $\omega_{1}=10 \mathrm{rad} \cdot \mathrm{s}^{-1}$, pulsation of the airflow velocity is observed in the (II PSC), and in the (III PSC) - in an antiphase with the first one, yet, with a smaller amplitude of fluctuations.

In the pre-screen aspiration channel the velocity of fluctuations is very insignificant. This can be explained by the inertia of the air system and the position of the PSC. The II PSC and the III PSC work in parallel, and they are joined in the horizontal section 5 (Fig. 1). For the II PSC with the frequency of the input impact $\omega_{2}=10 \mathrm{rad} \cdot \mathrm{s}^{-1}$ and $\omega_{1}=\omega_{7}=0 \mathrm{rad} \cdot \mathrm{s}^{-1}$ : when the resistance of the grain layer changes, a similar picture is observed, as in the first case $\left(\omega_{1}=10\right)$ (Fig.3,a). The less amplitude of fluctuations in the I PSC because of the impact of pulsations in the II PSC is explained by the fact that the I PSC has a longer extension in comparison with the II PSC, and therefore it has greater resistance and inertia.

Besides, both in the first and in the second case (Fig. 3,a), the frequency change of the grain layer resistance in the II and III PSC has an insignificant impact upon the amplitude of the airflow velocity fluctuations in the channel of pre-screen aspiration I PSC. 


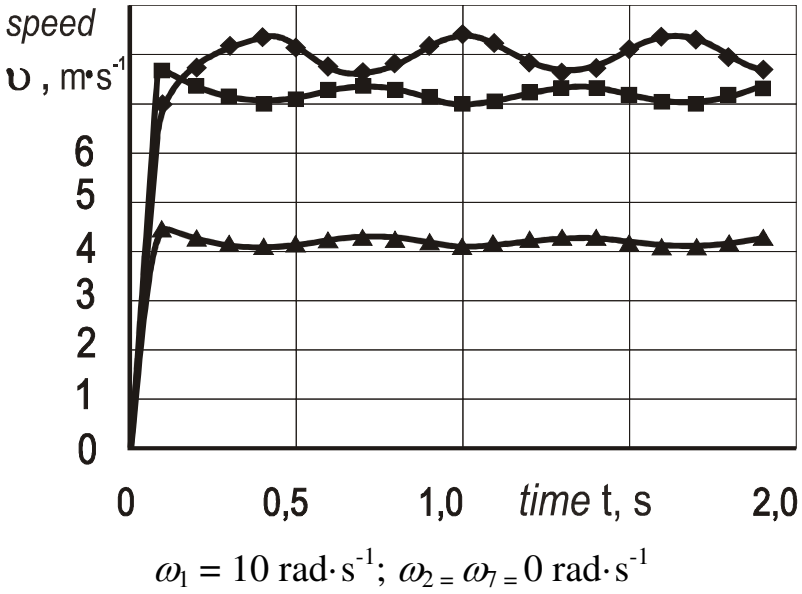

a)

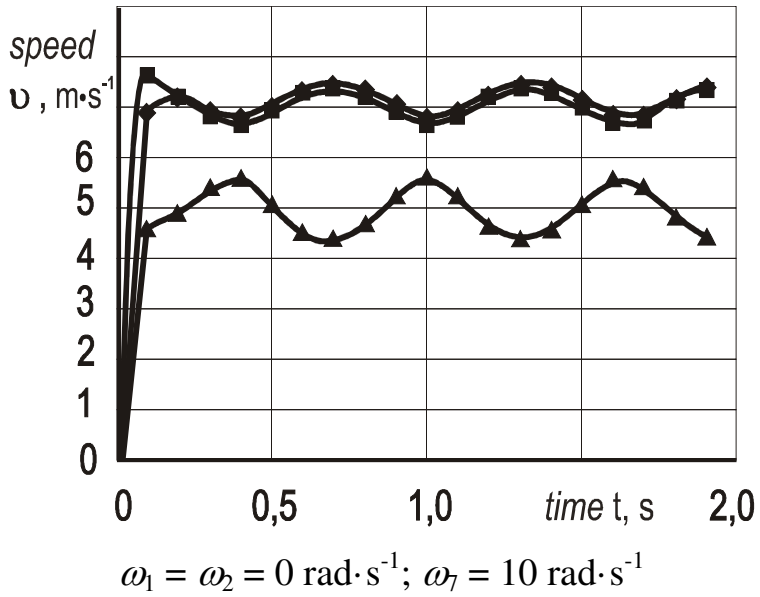

b)

Fig. 3. Change in airflow velocity $v$ in I PSC in time $t$ at various input frequencies of input impact $\omega: \_-$airflow velocity in I PSC; $\longrightarrow-$ - airflow velocity in II PSC; $\longrightarrow-$ airflow velocity in III PSC

The change in the frequency of the input impact in the pre-screen aspiration channel $\omega_{7}=10$ at $\omega_{7}=0, \omega_{2}=0$ (Fig.3,b) has a greater impact upon the pneumatic system. This is because the airflow rate in the I PSC is greater than in the II and III PSC (the depth of the pre-screen aspiration channel $h_{\mathrm{III}}$ пск $=0.18 \mathrm{~m}$, but that of the II and III PSC $h_{\text {II пск }}=h_{\text {I пск }}=0.125 \mathrm{~m}$ ). The amplitude of the airflow velocity fluctuations in the channel of the pre-screen aspiration is of greater importance than changing the frequency impact upon both the II and III PSC. The reason of this is less inertness of the pre-screen aspiration channel and its lower resistance (Fig. 3,c). When similar numerical studies of the pneumatic system with a decreased frequency of the input impact $\omega$ upon the PSC were carried out, smoother changes (pulsations) of the curves of the airflow velocity were obtained for the variation (pulsation) in the PSC in time at $\omega=0.75 \mathrm{rad} \cdot \mathrm{s}^{-1}$., i.e. a parameter of the frequency of the input impact $\omega$ of the pneumatic system of the grain cleaning machine was found, in which the airflow in its channels is stabilised.

The mathematical expressions (a system of equations) presented above make it possible to describe the dynamic characteristics of other elements of the pneumatic system and to find values of their design and technological parameters that allow stabilisation of the processes taking place in the pneumatic separating channels of the air system with their subsequent optimisation; for example, to regard the fan $B$ as an element of the pneumatic circuit, considering only the relation between its airflow rate $Q_{8}=U_{8} \cdot F_{8}$ and the difference in pressures at the inlet $P_{7}$ and the outlet $P_{8}$ from the device.

\section{Conclusions}

An air-screening machine has been developed for a fractional technology of forage grain flattening with a new implementation of the elements of the screen part and a pneumatic system, allowing efficient separation of the grain material coming from the field after threshing by combine harvesters into fractions of the seed and forage grain, and their qualitative cleaning from admixtures. There is presented a design and technological scheme of this machine in the form of a pneumatic circuit, the mathematical model of which allows theoretical testing the efficiency of the pneumatic system and analysis of the dynamic processes taking place in its separate elements, optimisation of the design and technological parameters of these elements, reducing the consumed time and financial means required to create an optimal scheme for the entire air system of the grain cleaning machine.

\section{References}

[1] Лачуга Ю. Рекомендации по заготовке и использованию высоковлажного фуражного зерна (Recommendations for the Preparation and use of Forage Grain with High Moisture Content), Moscow, 2006, 130 p. 
[2] Bulgakov V., Holovach I., Bandura V., Ivanovs S. A theoretical research of the grain milling technological process for roller mills with two degrees of freedom. INMATEH - Agricultural Engineering. Vol. 52(2) , 2017, pp. 99-106

[3] Vaculik, P., Maloun, J., Chladek, L., Poikryl, M. Disintegration process in disc crushers. Research in Agricultural Engineering. Volume 59, Issue 3, 2013, pp. 98-104.

[4] Smejtková A., Vaculík P. , Přikryl M. Rating of malt grist fineness with respect to the used grinding equipment. Research in Agricultural Engineering 62(3), 2016, pp. 141-146

[5] Русаков Р., Жвакина В., Тимкина Е., Одегов В. Влияние плющения и консервирования зерна ржи на его химический состав и питательную ценность (Impact of the rye grain flattening and preservation upon its chemical composition and nutritional value), Материалы научной сессии Кировского филиала PAE (Collection "Materials of the scientific session "), Kirov, 2004, pp. 275-276.

[6] Sysuev V., Ivanovs S., Savinyh P., Kazakov V. Movement and transformation of grain in twostage crusher. Engineering for Rural Development, Proceedings, Vol.14, 2015, pp. 22-27.

[7] Dal-Pastro E., Facco P., Bezzo E., Zamprogna E., Barolo M., Data-driven modelling of milling and sieving operations in wheat milling process. Food and Bioproducts Processing, Vol.99, 2016, pp. 99-108.

[8] Bavram M., Oner M. Bulgur milling using roller, double disc and vertical disc mills, Journal of Food Engineering, vol.79(1), 2014, pp.181-187;

[9] Бурков А.И. Разработка и совершенствование пневмосистем зерноочистительных машин (Development and improvement of pneumatic systems of the grain cleaning machines). Kirov, 2016, $380 \mathrm{p}$.

[10] Patent RU №2513391. Машина для фракционирования и очистки от примесей зернового материала (A machine for fractionation and cleaning of the grain material from admixtures). Авторы: Сычугов Н., Сычугов Ю., Казаков В., 2014.

[11]Гликман Б. Математические модели пневмогидравлических систем (Mathematical models of pneumohydraulic systems). Moscow, 1996, 368 p.

[12]Зенкевич О., Морган К. Конечные элементы и аппроксимация (Finite elements and approximation), (trans. from engl.), Moscow, 1986, $316 \mathrm{p}$. 